\title{
THOMAS MANN: UM CLÁSSICO DA MODERNIDADE*
}

\author{
Eloá Heise**
}

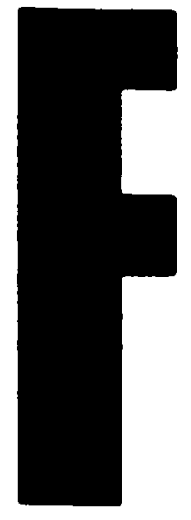

alar de Thomas Mann e seu tempo equivale a falar de um período literário conhecido como modernismo, um movimento difuso no tempo e no espaço, que engloba vários círculos estéticos e nāo pode ser entendido como manifestaçāo una e coerente. O modernismo abarca idéias vindas de muitas fontes, geradoras de diferentes versōes de uma arte nova e que, apesar das divergências, mostram uma rede de interdependências e afinidades. Esse período pode compreender, por exemplo, desde um romancista russo do século passado como Dostoiévski até um escritor checo, que escre-

* Este artigo foi apresentado sob forma de palestra no curso de Extensāo Universitária ministrado na Universidade Federal do Paraná nos dias 26 e 27 de abril de 1990 so. bre o tema "Thomas Mann e seu tempo".

** Universidade de São Paulo. 
via em alemāo, ainda hoje nāo divulgado em sua terra natal, como Kafka. Dentro desta lista poderíamos incluir lbsen ou Proust, T. S. Eliot ou Joyce e outros mais, imāos estéticos de Thomas Mann que, a despeito de enormes diferenças estilísticas e temáticas, merecem ser incluídos dentre os clássicos da modernidade, pois suas obras estabeleceram os parâmetros que norteiam nosso conceito de "mundo moderno".

Como marcos limites do modernismo podemos fixar, com propósitos claramente didáticos, o período que se estende da virada do século (1870) até o início da Segunda Guerra Mundial. E, se ainda quisermos vincular o movimento à figura de Thomas Mann, veremos que esse espaço de tempo praticamente coincide com a vida do autor, nascido em 1875 e falecido em 1955.

O modernismo, como transformação radical sofrida pelas formas, pelo espírito e pela natureza das artes, representa uma crise na história do humanismo ocidental e uma tentativa séria de compreender a natureza da existência moderna. Este conceito liga-nos, de imediato, ao adjetivo moderno, qualificativo usado de forma abrangente para designar o nosso tempo mas que, paralelamente, traz consigo conotaçōes de desorientação, indefinição e desrraigamento. $O$ moderno, fenômeno conseqüente da modernizaçāo, originou-se do excepcional progresso material resultante do processo de racionalizaçāo e desenvolvimento tecnológico e científico. A modemização trouxe consigo o progresso e ampliou as possibilidades de alcance de bens materiais mas, por paradoxal que pareça, nāo conseguiu preencher as expectativas de realizaçāo existencial, ao contrário, o racionalismo acabou por cercear a liberdade individual, a razāo culminou por converter-se em instrumento de poder e opressāo.

Ao homem, desindividualizado, restou a sensação de desencanto e vazio existencial. Já na primeira metade do século XLX, na época do Romantismo, configura-se a discordância entre as aspirações individuais e a modernizaçāo presente. A partir de entāo, os ciclos estéticos, especialmente no campo da literatura, sāo caracterizadores de crises. No ciclo pós-romântico (segunda metade do século XIX) há novas dissonâncias entre a modernização social e a cultura em termos estéticos. O impressionismo, por exemplo, emerge no momento da Segunda Revoluçāo Industrial (1875-1895), em meio à grande depressão vivida pelo capitalismo ocidental. No século XX, na era da máquina, acirram-se os conflitos, os interesses e conseqüentemente as crises. Os ciclos estéticos da modernidade, as vanguardas do século XX (Futurismo, Cubismo, Expressionismo, Dadaísmo. Surrealismo) sāo todos sinalizadores de uma crise que passa a adquirir caráter permanente. Várias das pesquisas formais 
que caracterizam a revolução modernista no campo da literatura: as formas fragmentárias, a paródia, as estruturas nāo convencionais, a ambigüidade, a ironia, o grotesco, são alguns dos recursos estilísticos que materializam esta consciência de crise. NIETZSCHE, o filosofo mentor da modernidade, afirmou que os homens modernos são "filhos de uma época fragmentada, pluralista, doente e estranha."

$O$ imperativo de tentar compreender a natureza da existência moderna tornou-se uma necessidade imperiosa a partir da transiçāo sofrida pelo mundo ocidental ao passar do século XIX para o século $\mathrm{XX}$. Os poetas que vinham discutindo a crise da palavra perceberam que havia também uma crise de mundo. Abruptamente a unidade que caracterizava o século XIX foi desfeita. O indivíduo e o mundo, apesar de representarem até entāo um dualismo antagônico, formavam uma totalidade entendível, explicada pela física e pela psicologia tradicional. Ao ingressar no século $\mathrm{XX}$ a humanidade entra em um multiverso, nāo mais em um universo. Este é um tempo cultural e socialmente multifacetado que nos legou nossas maiores realizaçōes e nossos piores desastres. Na virada do século nāo se tem um mundo estável, mas um território onde as fronteiras, as classes, os valores e as idéias estavam em mutação. À mudança do mundo exterior correspondia a consciência de que o mundo interior também se modificara.

O conceito de "tornar novo", premissa fundamental que deveria nortear a arte moderna segundo Ezra POUND, nāo significava apenas a necessidade de procura por algo original e singular, mas a obrigação que se impunha a arte de ir à frente de sua época, transformando-a, ao mesmo tempo que se transformava a si mesma. Com isso rompia-se a ligação com o passado e estabelecia-se um vínculo com o presente e, acima de tudo, com o futuro. Em suma, a arte do "tomar novo" não é apenas um evento estético; decorre de mudanças sociais, ideológicas, de formas de vida, numa atmosfera de ruptura que caracterizou a transiçāo entre duas eras.

Exatamente esse momento de transição e ruptura entre as tradiçōes do século XIX e o mundo fragmentário do século XX é um dos temas constantes da literatura modernista e, em especial, de Thomas Mann. Várias obras do autor têm como núcleo temático a difícil aventura do artista modemo, entre o clássico e o romântico, entre o burguês e o artista, entre o mundo arcaico do século XIX e o mundo moderno do século XX. Os protagonistas dos romances de Mann são freqüentemente artistas em conflito com forças antagônicas como é o caso de Adrian Leverkühn, personagem central do romance Doutor Fausto, dilacerado entre os instintos e o intelecto, ou entāo o de Tonio Kröger, figura principal da novela de mesmo no- 
me, dividido entre o sólido mundo material burguês e o mundo estético que, por sua própria natureza, questiona a visāo materialista da existência. Na obra do autor há, como consequiência deste conflito central, a busca por uma unidade inatingivel: seu tema é a procura pela reconciliaçāo moderna.

As grandes narrativas do século XIX estavam associadas a crises religiosas e morais. O escritor do novo século nāo mais seria um moralista burguês, mas um instrumento independente de evoluçāo criadora. Na virada do século os artistas se autodenominavam "decadentes" mostrando uma percepçāo moderna ao encararem a si mesmos como transição: um fin du siecle consciente de sua própria morte. Essa mesma sensação de fim de época é mostrada por Thomas Mann em seu primeiro grande romance, ainda de cunho realista, os Buddenbrooks, onde se relata a decadência de uma família burguesa. Posteriormente essa consciência de decadência é acrescida de uma percepçāo de declínio histórico e da total fragilidade humana no periodo de pós-guerra, levando o autor a tentar fugir da prisão do tempo histórico através do tempo mítico. Basta lembrar sua obra manifestamente mitológica: José e seus irmãos.

No multiverso do século XX a cultura da modernidade vai ser marcada pelo desenvolvimento autônomo da ciência, da moral e da arte; busca-se, mais do que nunca, a experimentaçāo, a invençāo. A arte passa a exprimir a si mesma, seus próprios métodos de composiçāo, libertando-se da representação realista. Nāo se quer mais representar, mas sim interpretar. Como conseqüência tem-se o fim da figuraçāo, o uso da deformação, da fragmentação, da abstraçāo, da assimetria, da incongruência.

Dentre as experiências ousadas e procura de novas formas de expressāo pode-se mencionar o exercício da metalinguagem, ou seja, o texto centrado em seu próprio fazer. A vasta obra de Thomas Mann também apresenta como uma de suas constantes esta preocupação metalingüística. Tanto em obras da juventude como em obras da maturidade vamos encontrar a discussão sobre o problema da arte e a procura por seu sentido: Tonio Kröger (1903), A morte em Veneza (1912). Doutor Fausto (1947), As confissöes do impostor Felix Krull (1954).

A inclusāo desse tema abstrato em um gênero épico como o romance ou a novela onde, em princípio, se espera a narraçăo de fatos vivenciados, aponta para mais uma das características da modernidade literária na obra de Mann: a liberdade plena de criaçāo com a possibilidade de abordar todos os assuntos, e a inserção de passagens ensaísticas em um texto narrativo. Na novela Tonio Kröger, por exemplo, encontramos um estilo claramente ensaístico no capítu- 
lo IV, quando se chega a uma bela definição da função de literatura que, com seu efeito purificador, destrói "as paixōes através do reconhecimento e da palavra, a literatura como caminho para a compreensão, para o perdão e para o amor."

Esta citação, que menciona a palavra como elemento chave da literatura, pode ressaltar mais um tema fundamental da poética de Thomas Mann: a música. A linguagem e a música são variantes do mesmo código, pois a linguagem, quando verdadeiramente apreendida aspira à condição de música. A consciência da crise da palaura, herdada pelos poetas modernistas desde o Simbolismo, a palavra que tende ao silêncio, metáfora da situaçāo literária moderna, tranforma-se, na obra de Mann, em uma opção pela música. Música não só no sentido de alguns de seus protagonistas serem músicos, o arquétipo do artista. No caso de Thomas Mann a música chega a influenciar a própria estrutura de obras como de Tonio Kröger, novela construída com as mesmas etapas de uma sonata, ou de Doutor Fausto, romance estruturado sob a forma de música polifônica. $\mathrm{Na}$ música, muito mais que na linguagem, as convenções estéticas atingem a intensidade máxima de seu ser, é a própria "ambigüidade como sistema" (Doutor Fausto). Também a obra de Mann foi escrita sob o signo da ambigüidade. A equivalência entre música e linguagem manifesta-se explicitamente em Doutor Fausto, onde a música é descrita como aquela "linguagem maravilhosa e inarticulada" que "tudo e nada diz" a quem cabe a "tarefa de exprimir a situaçāo do espírito, mesmo em nossa época, profundamente crítica." Assim a palavra, ou melhor, a música, como forma mais pura de poesia, tende a atingir seus limites, apontando para o silêncio, metáfora da literatura moderna. Doutor Fausto representa o ponto de maior criticidade em relação à palavra, pois discute a superioridade da música que, com suas modalidades polifônicas, alcança maior autonomia dos suportes realistas do que a narrativa verbal, baseada na linguagem.

O modernismo, por ser um movimento prolongado, esteve em constante mutaçāo ao longo de seus, digamos, sessenta anos. A Primeira Guerra Mundial, um marco decisivo da época, materializou as premoniçōes sinistras dos poetas da virada do século e deu um novo sentido à idéia de grande ruptura. A partir de 1914 o caráter humano mudou. O moderno nāo era mais uma experiência ousada de novas formas de expressāo, mas a objetivaçāo de uma nova situação macabra. Hans Castorp, o protagonista de $A$ montanha mágica, saindo de seus conflitos espirituais no mundo protegido da montanha para lutar nos campos de batalha, sintetiza bem a nova situação: "Onde estamos? Para onde nos arrastou o sonho? Penumbra, chuva, imundice." 
A montanha mágica é um romance divisor de águas, nāo só dentro do movimento modernista, mas também na obra de Thomas Mann. Em relaçāo ao modernismo, esta foi uma das grandes obras iniciada na atmosfera experimentalista de antes da guerra e que só foi concluída depois de terminado o conflito. No que se refere à produção de Thomas Mann, esta obra representa um elo entre o romance de cunho realista da juventude, Buddenbrooks, e a obra de cunho mitológico, José e seus irmāos.

Com José e seus imãos o autor reproduz um processo suprahistórico, onde o protagonista é afastado da posiçāo de um eu absoluto, para desembocar em um eu coletivo. Também em Doutor Fausto temos a manifestação de estruturas arquetípicas. Adrian Leverkühn não se torna visível como indivíduo, mas sim como encarnaçāo da lenda, sem face própria, uma personagem constituída de forças antagônicas: os instintos e o intelecto.

A partir dos anos de 1920. com obras que tendem a visar cada vez mais o mito, Thomas Mann mostra mais uma faceta característica do estilo modemista: a crise do romance psicológico. No romance de cunho psicológico as personagens recebem contomos firmes e se movimentam em um mundo temporal e especialmente delimitado. A análise psicológica, baseando-se na causalidade, pressupōe uma narrativa ancorada em uma fábula, em um enredo coerente. A dúvida em relaçāo à unidade da pessoa e à ordem do mundo levam à eliminaçāo de uma trama coerente. Nāo estamos mais diante de personagens, mas sim de processos psíquicos exemplares. Em uma obra como a de Kafka, por exemplo, não há profundidade psicológica. A personagem empírica é destruída. em seu lugar tem-se a apresentaçāo de situaçōes limites. Com isso nāo há desenvolvimento do tempo. Os romances e narrativas de Kafka, para mantermos o mesmo exemplo, nāo avançam: o leitor esbarra sempre em situações fundamentais que se repetem de forma circular. É exatamente esta falta de um centro interno coerente que leva à crise do romance psicológico, fenômeno análogo ao que acontece $\mathrm{com}$ a pintura aperspectiva ou com a música sem um centro tonal.

O periodo dos anos de 1920 foi uma época de grandes lançamentos modemistas. Só para citar alguns: Ulisses de James JOYCE, Terra estéril de T. S. ELIOT, mais um volume de $A$ procura do tempo perdido de PROUST, Sonetos de Orfeu de RILKE, todos publicados em 1922. Em 1924 publica-se $A$ montanha mágica de Thomas MANN e $O$ artista da fome de KAFKA. Em 1925 surge no mercado $O$ processo de KAFKA e, à guisa de brutal contradiçāo, Minha luta de HITLER. A mençāo desta obra de Hitler, serve para ilustrar a grande ameaça que pairava por sobre toda a atmosfera de 
livre criação e experimentação do modernismo: a ascençāo do nazifascismo.

As obras dos anos de 1920 caracterizam-se por grandes pretensōes literárias e refletem, mais do que nunca, um angustiado desespero moderno. São obras irônicas, fragmentadas, com personagens objetos e não sujeitos do mundo e de seus atos. Na poesia domina o verso livre, na prosa o "fluxo de consciência", a citação e a montagem articulam a estrutura textual.

No fim dos anos de 1920 , com o grande crash de 29 , com a depressāo econômica e a ascençāo do fascismo, o espírito crítico do modernismo perde sua razāo de ser. A Segunda Guerra, que vinha se anunciando, eclodiu em setembro. O movimento que se autodenominava "modemo" e que deveria ser eternamente moderno chega ao fim. As mais preciosas manifestaçōes modernistas em todos os campos artísticos passaram a ser execradas pelos nazistas como "arte degenerada".

A vivência da Segunda Guerra faz com que se reconheça, mais do que nunca, a pertinência da visão modernista de crise, o acerto de sua ironia trágica, a legitimidade de sua rejeição da própria época. Por isso mesmo é que suas formas são sempre as mais contundentes e críticas como a ironia de um Thomas Mann, a tragicomédia de um Pirandello, a paródia de um T. S. Eliot, a fragmentação estética de um Proust, ou ainda o absurdo existencial de um Kafka. Também há motivos para que a ausência de valores arraigados a um único mundo fechado e provinciano componha uma das facetas das realizaçōes modernistas. Os grandes representantes desse movimento, seja Thomas Mann, Ezra Pound, T. S. Eliot, Pirandello, James Joyce e outros, são todos cidadāos do mundo que emprestaram ao movimento um caráter essencialmente cosmopolita, com obras que têm por cenário o palco das grandes cidades, um espaço de imensas possibilidades, mas também de crise e esterilidade.

O modernismo continua sendo vital, nāo apenas como a tradiçāo mais próxima a nós, mas porque também nós, na virada de um outro século, vivemos em um tempo cosmopolita e politicamente cático, carregando conosco a mesma sensação de fragmentação e estranheza. A grande importancia da modernidade é que nos torna, hoje, pós-modernos, designaçāo onde a palavra-chave $\epsilon$ o conceito modernidade, mostrando que este $\epsilon$, ainda hoje, nosso referencial poético. 


\section{RESUMO}

A modernidade, sinônimo de modernismo, é caracterizada como um movimento difuso no tempo e no espaço, que abarca idéias vindas de muitas fontes mas que, apesar das diferenças, mostram uma rede de interdependências e afinidades. $O$ periodo é demarcado a partir da virada do século até o início da Segunda Guerra Mundial e representa não só uma crise na história do humanismo ocidental, mas também a consciência dessa crise. Assim suas formas são sempre as mais contundentes e críticas como a ironia de um Thomas Mann, a tragicomédia de um Pirandello, a paródia ade um T. S. Eliot, a fragmentaçāo estética de um Proust, $o$ absurdo existencial de um Kafka.

\section{REFERÊNCIAS BIBLIOGRÁFICAS}

1 BRADBURY, Malcolm O mundo moderno. Sāo Paulo : Companhia das Letras, 1989.

2 BRÄUTIGAM, Kurt. Thomas Mann: Tonio Kröger. München : R. Oldenbourg Verlag, 1969.

3 HASSELBACH, Karlheinz. Thomas Mann: Doktor Faustus. München : R. Oldenbourg Verlag, 1988.

4 PROENÇA FILHO, Domício. Pós-modernismo e literatura. São Paulo: Ed. Ática, 1988.

5 ROSENFELD, Anatol. À procura do mito perdido. In: Doze estudos. São Paulo: Conselho Estadual de Cultura, [s.d.] p.31-41.

6 SANTOS, Jair Ferreira dos. O que é pós-moderno. Sāo Paulo : Brasiliense. 1986.

7 STEINER, George. Linguagem e silêncio: Ensaios sobre a crise da palavra. São Paulo : Companhia das letras, 1989. 